Critical Chemical-Mechanical Couplings that Define Permeability Modifications in Pressure-Sensitive Rock Fractures

Derek Elsworth, Abraham Grader, Susan Brantley

Penn State University

University Park, PA 16802

Final Report

For Period September 15, 2000 - November 14, 2004

DE-FG02-00ER15111

April 2007 


\section{Critical Chemical-Mechanical Couplings that Define Permeability Modifications in Pressure- Sensitive Rock Fractures}

\section{Derek Elsworth, Abraham Grader, Susan Brantley \\ Penn State University}

\section{Table of Contents}

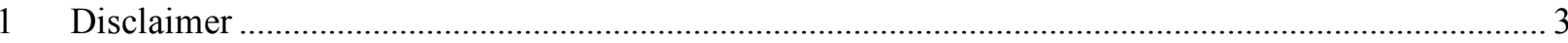

2 Executive Summary/Project Description ......................................................................................... 4

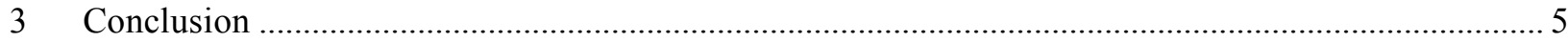

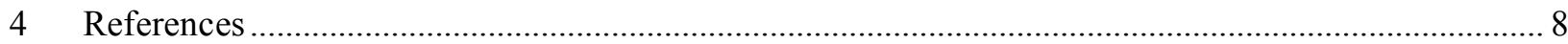

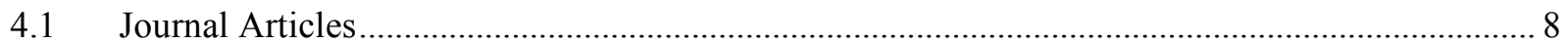

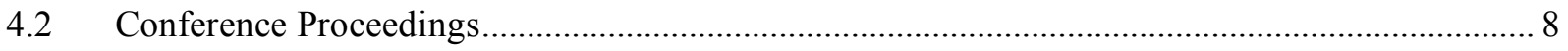

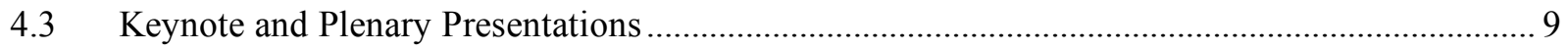

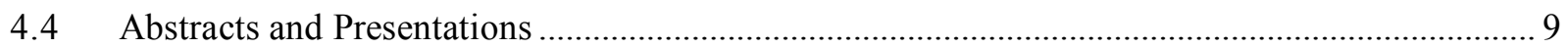

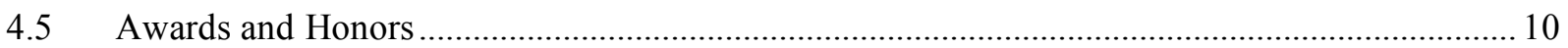




\section{DisClaimer}

This report was prepared as an account of work sponsored by the United States Government. Neither the United States nor the United States Department of Energy, nor any of their employees, nor any of their contractors, subcontractors, or their employees, makes any warranty, express or implied, or assumes any legal liability or responsibility for the accuracy, completeness, or usefulness of any information, apparatus, product or process disclosed or represents that its use would not infringe privately-owned rights. 


\section{EXeCUTIVE SUMMARY/ProJeCT DESCRIPTION}

This work examined and quantified processes controlling changes in the transport characteristics of natural fractures, subjected to coupled thermal-mechanical-chemical (TMC) effects. Specifically, it examined the effects of mineral dissolution and precipitation mediated by mechanical effects, using laboratory through-flow experiments concurrently imaged by X-ray CT. These were conducted on natural and artificial fractures in cores using water as the permeant. Fluid and mineral mass balances are recorded and are correlated with in-sample saturation, porosity and fracture aperture maps, acquired in real-time by X-ray CT-imaging at a maximum spatial resolution of 15-50 microns per pixel. Post-test, the samples were resin-impregnated, thin-sectioned, and examined by microscopy to define the characteristics of dissolution and precipitation. The test-concurrent X-ray imaging, mass balances, and measurements of permeability, together with the post-test microscopy, were used to define dissolution/precipitation processes, and to constrain process-based models. These models define and quantify key processes of pressure solution, free-face dissolution, and shear-dilation, and the influence of temperature, stress level, and chemistry on the rate of dissolution, its distribution in space and time, and its influence on the mechanical and transport properties of the fracture. 


\section{Conclusion}

Prior studies have examined the important factors controlling the interaction of mechanically- and chemically-mediated processes that modify the transport properties of natural fractures in rock. We have used tightly-constrained laboratory flow-through reactor studies to develop process-based models for observed permeability histories at prescribed normal stresses $(0-3 \mathrm{MPa})$, temperatures $\left(20^{\circ} \mathrm{C}\right.$ $\left.150^{\circ} \mathrm{C}\right)$, flow rates $(0-2 \mathrm{cc} / \mathrm{min})$, and chemical potentials $\left(\mathrm{H}_{2} \mathrm{O}\right.$ at $\left.\mathrm{pH} \sim 5-7\right)$.

Linkage between changes in porosity and permeability is constrained by multiple independent measurements that define an over-constrained system. Changes in porosity are indexed by measured changes in fluid and dissolved mass efflux, and by periodic imaging by X-ray $\mathrm{CT}$ with a voxel resolution to $\sim \mathrm{O}(40 \mu \mathrm{m})$. Final porosities are anchored by resin impregnation and thin-sectioning, with some tests including SEM of surfaces and pre-and post-test comparisons of fracturesurface profilometry (resolution $\pm 15 \mu \mathrm{m}$ horizontally, $0.5 \mu \mathrm{m}$ vertically).

Results on novaculite (99\% quartz) have shown that changes in permeability can be both large $\sim \mathrm{O}(\times 100)$, and of surprising sense - permeabilities reduce as mineral mass is net removed from the sample by dissolution (Polak et al., 2003). Surprisingly, these changes can occur at modest temperatures $\left(\sim 80^{\circ} \mathrm{C}\right)$ and stresses $(\sim 3.5 \mathrm{MPa})$. These results are illustrated in Figure 1 for water circulation at constant flow rate $(2 \mathrm{cc} / \mathrm{min})$. As temperatures are incremented from $20^{\circ} \mathrm{C}$ through $150^{\circ} \mathrm{C}$, the fracture monotonically closes despite net removal of silica at $\sim 1 \mathrm{ppm}$ in the effluent. The fivefold reduction in fracture aperture is measured in the flow response as a permeability reduction of two orders of magnitude, for the 41 day test. Notably, permeability reduces, despite net dissolution throughout the test. This

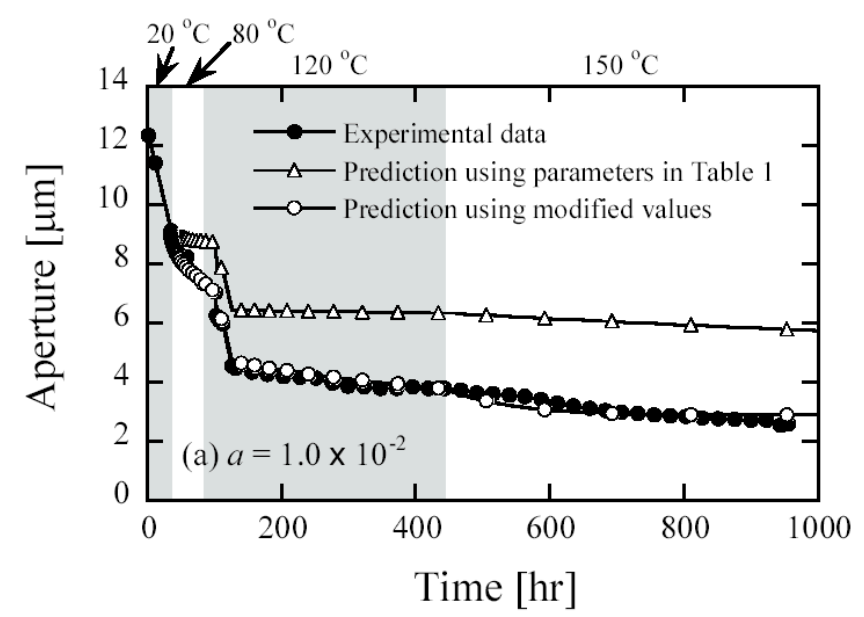

Figure 1. Change in aperture for circulation of water at 2 $\mathrm{cc} / \mathrm{min}$ in novaculite at incremented temperatures. Experimental data filled circles. Model results as open triangles and circles.

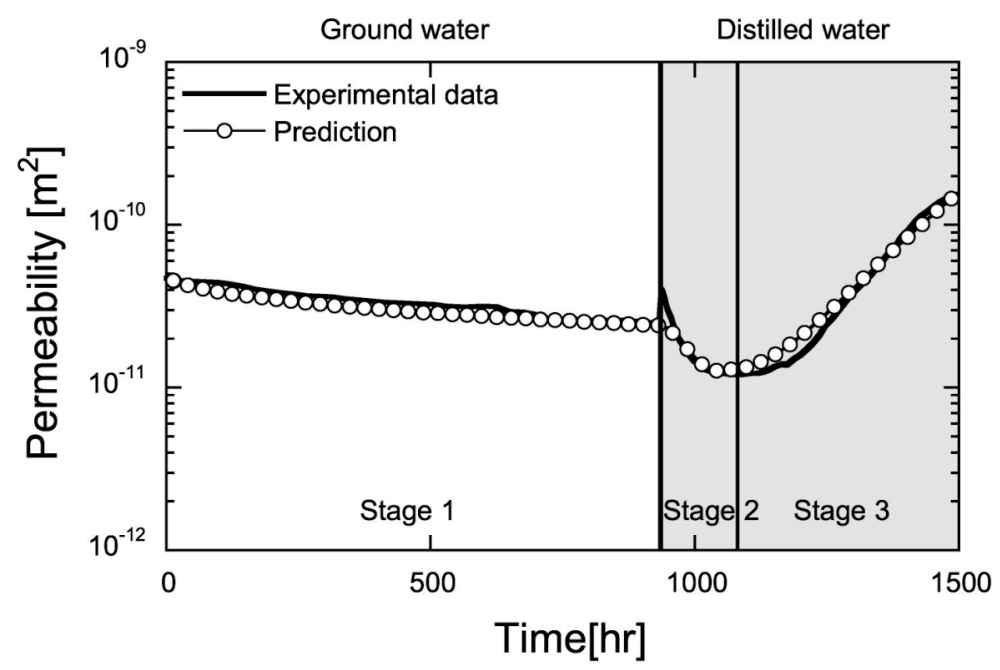

Figure 2. Change in permeability with time for continuous flow at 2 $\mathrm{cc} / \mathrm{min}$ through a fracture in Bellefonte limestone. Test at invariant low temperatures $\left(\sim 20^{\circ} \mathrm{C}\right)$ and effective stresses $(\sim 3.5 \mathrm{MPa})$. Influent water changed at $935 \mathrm{~h}$ from groundwater ( $\mathrm{pH} \sim 8$, unshaded panel) to distilled water $(\mathrm{pH} \sim 6$, shaded). At $935 \mathrm{~h}$ a brief sharp increase in permeability (seating due to effective stress interruption), is followed by a coherent decrease in permeability, that ultimately arrests as a single flow conduit develops, and permeability climbs. Understanding the interacting phenomena that control this spontaneous response under invariant test conditions is the focus of this proposed study. 
surprising response results from the elevated dissolution of bridging asperities under the constant applied effective stresses. Closure is reactivated as the system temperature is incremented. For each temperature increment, closure ultimately halts as asperity stresses are reduced as the asperity contact area grows, and the excess chemical potential in the contact region diminishes (Yasuhara, et al., 2004). This observed response highlights the complex and poorly constrained behavior where stress and chemical effects are important. Our interest is to further explore these important processes for fractures both far-from-failure, and critically-stressed, and where interactions between mechanical and chemical effects are important.
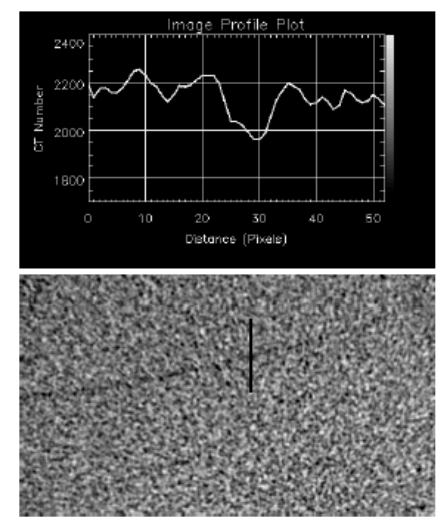
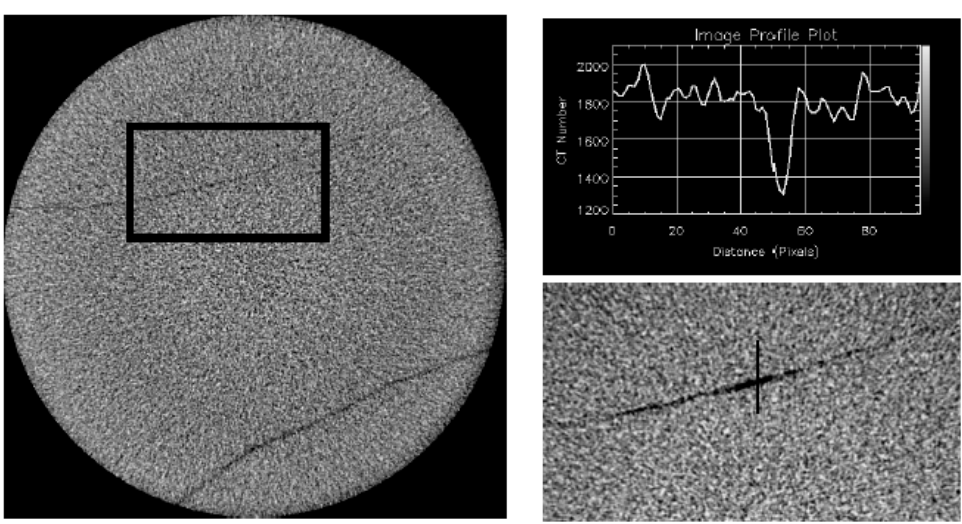

Figure 3. Micro-CT-scans of the full core (Figure 2) taken pre-test (center) with marked zone used for zoom-in both before (left) and at the end of the test (right). Graphs show the variation in CT-number across the fracture, and the focusing of dissolution in a single 'wormhole.'

Similar effects are apparent in other facies, such as carbonates (Polak et al., 2004), again illustrating the competition between free-face dissolution and stress-mediated dissolution (pressure solution), but now at low relative temperatures. Figure 2 shows changes in permeability of a fracture in limestone that result from the circulation of water at constant rate $(2 \mathrm{cc} / \mathrm{min})$, and at constant stress, with a change in $\mathrm{pH}$ from $\sim 8$ to $\sim 6$ at 925 hours into the test. Notably, permeability reduces as calcium is net removed from beneath bridging asperity contacts, and this accelerates as the $\mathrm{pH}$ of the influent water drops from $\sim 8$ to $\sim 6$. Ultimately, the fracture closure is sufficient to localize flow into a single un-occluded flow channel, and free-face etching becomes the dominant process in the system, resulting in a spontaneous switch in permeability, and the development of a throughgoing flow channel (a wormhole). The presence of this feature is confirmed by concurrent X-ray CT (Figure 3), and by post-test sectioning, and is congruent with fluid flux and mass efflux measurements. These constraints allow the principal operative processes - the competition between free-face and stress-mediated dissolution - to be adequately modeled.

Spontaneous changes in permeability under invariant effective stresses are also apparent in less-soluble rocks (Yasuhara et al., 2004). Cycling of temperatures and flow rates on an isostatically-stressed natural fracture in novaculite, yields first fracture closure, then fracture widening, with mass net removed from the fracture throughout the test (Figure 4). This illustrates the extreme sensitivity of the long-term permeability of fractures to the ambient fields and paths of stress, temperature, chemical potential, and flow rate. 


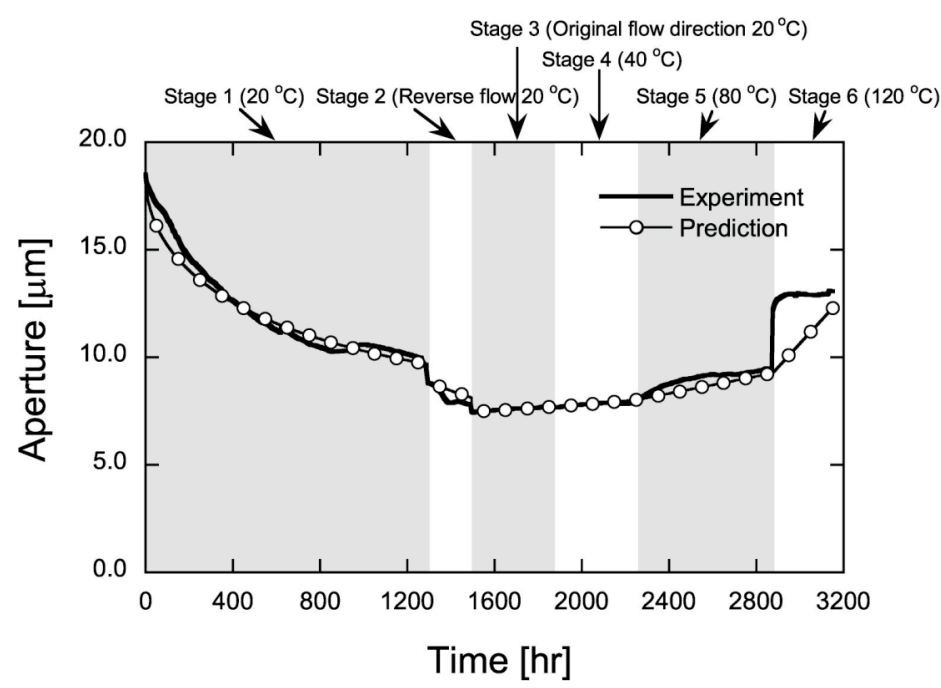

Figure 4: Evolution of permeability for water circulation in a fracture in novaculite under constant stress, with variable flow rates.
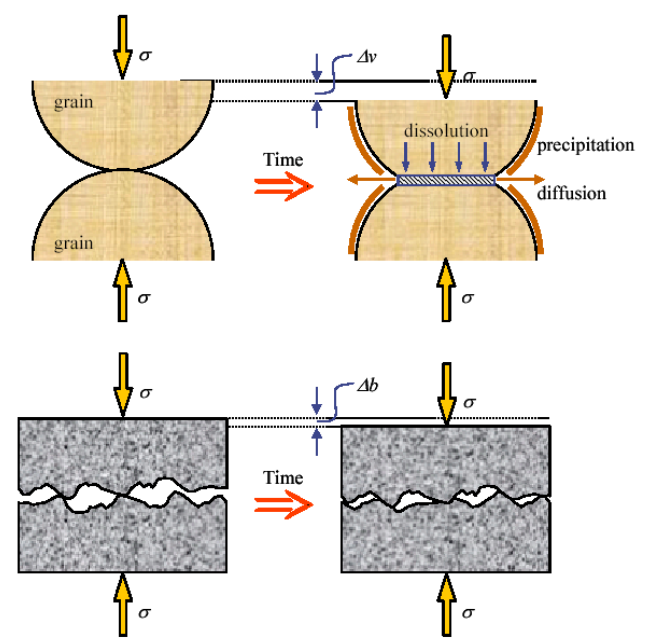

Figure 5. Analog between grain interpenetration and stress- and chemistrymediated aperture closure.

These observed, but anomalous, changes in permeability may be represented by incorporating the role of stress-mediated dissolution at asperity contacts into the overall behavior; closure controls permeability reduction, and incorporates the serial processes of dissolution at contacting asperities, interfacial diffusion, and precipitation at the free face of fractures (Yasuhara et al., 2003). These processes progress over a representative contacting asperity and define compaction at the macroscopic level (Figure 5), together with evolving changes in solute concentration for arbitrarily open or closed systems for prescribed ranges of driving effective stresses, equilibrium fluid and rock temperatures, and fluid flow rates. Measured fracture surface profiles are applied to define simple relations between fracture wall contact-area ratio and fracture aperture that represents the irreversible alteration of the fracture surface geometry as compaction proceeds. These lumped parameter models are thermodynamically selfconsistent, and show agreement with observations in novaculite (Yasuhara et al., 2004), tracking changes in fracture aperture (Figure 1) and concentrations of the interstitial fluid, and confirming pressure solution as the dominant mechanism. Behavior is strongly conditioned by ambient stress and temperature fields, chemical potential of the solute, and its volumetric flux (Yasuhara et al., 2004)(Figure 4). For the dissolution-dominated systems considered, fracture closure rates have been shown to scale roughly linearly with stress increase, and exponentially with temperature increase - taking between days and decades for closure to reach completion.

These results are documented in the articles which were an outgrowth of this project, noted in the following. 


\section{REFERENCES}

\subsection{Journal Articles}

1. Yasuhara, H., Elsworth, D., Polak, A., Liu, J., Grader, A., and Halleck, P. (2006) Spontaneous Permeability Switching in Fractures in Carbonate: Lumped Parameter Representation of Mechanically- and Chemically-Mediated Dissolution. Transport in Porous Media. Vol. 65, pp. 385409.

2. Yasuhara, H., and Elsworth, D. (2006) A numerical model simulating reactive transport and evolution of fracture permeability. Int. J. Num. and Anal. Meth. in Geomechs. Vol. 30, No. 10, pp. $1039-1062$.

3. Elsworth, D., and Yasuhara, H. (2006) Short timescale chemo-mechanical effects and their influence on the transport properties of fractured rock. Pure and Appl. Geophys. Vol. 163, pp. 2051 - 2070. DOI 10.1007/s00024-006-0113-3

4. Yasuhara, H., Polak, A., Mitani, Y., Grader, A., Halleck, P., and Elsworth, D. (2006) Evolution of fracture permeability through fluid-rock reaction under hydrothermal conditions. Earth and Planetary Science Letters. Vol. 244, pp. 186 - 200.

5. Yasuhara, H., Polak, A., Mitani, Y., Grader, A., Halleck, P., and Elsworth, D. (2005) Evolution of fracture permeability through reactive flow at elevated temperature. Trans. Geotherm. Res. Council. Vol. 29, pp. $437-441$.

6. Yasuhara, H., Marone, C., and Elsworth, D. (2005) Fault zone restrengthening and frictional healing: the role of pressure solution. J. Geophys. Res. Vol. 110, B06310, doi:10.1029/2004JB003327.

7. Polak, A., Elsworth, D., Liu, J., and Grader, A. (2004) Spontaneous switching of permeability changes in a limestone fracture under net dissolution. Water. Resour. Res., Vol. 40, W03502, doi:10.1029/2003WR002717.

8. Yasuhara, H., Elsworth, D., and Polak, A. (2004) The evolution of permeability in a natural fracture: significant role of pressure solution. J. Geophys. Res., Vol. 109, B03204, doi:10.1029/2003JB002663

9. Yasuhara, H., Elsworth, D., and Polak, A. (2003) A mechanistic model for compaction of granular aggregates moderated by pressure solution. J. Geophys. Res. 108(B11), 2530, doi:10.1029/2003JB002536.

10. Polak, A., Elsworth, D., Yasuhara, H., Grader, A.S., and Halleck, P.M. (2003) Permeability reduction of a natural fracture under net dissolution by hydrothermal fluids, Geophys. Res. Lett., 30(20), 2020, doi:10.1029/2003GL017575.

\subsection{Conference Proceedings}

1. Yasuhara, H., Elsworth, D., and Polak, A. (2003) Compaction and diagenesis of sandstones the role of pressure solution. GeoProc 2003. Proc. Int. Conf. on Coupled T-H-M-C Processes in Geosystems. Stockholm, Sweden, October, pp. 731 - 736.

2. Polak, A., Yasuhara, H., Elsworth, D., Liu, J., Grader, A., Halleck, P. (2003) The evolution of permeability in natural fractures - the competing roles of pressure solution and free-face dissolution. GeoProc 2003. Proc. Int. Conf. on Coupled T-H-M-C Processes in Geosystems. Stockholm, Sweden, October, pp. 719 - 724.

3. Liu, J., Mallett, C., Beath, A., Elsworth, D., and Brady, B.H.G. (2003) A fully coupled flowtransport-deformation model for underground coal gasification. GeoProc 2003. Proc. Int. 
Conf. on Coupled T-H-M-C Processes in Geosystems. Stockholm, Sweden, October, pp. 609 614.

\subsection{Keynote and Plenary Presentations}

1. Liu, J., Sheng, J.C., Zhu, W.C., Elsworth, D., Liu, J.X., Liao, Q.L., and Brady, B.H.G. (2006) Effects of heterogeneity on the multiphysics of fractured rocks. Proc. GeoProc 2006. [Keynote Lecture].

2. Elsworth, D., Yasuhara, H., Polak, A., and Liu, J. (2005) Short timescale chemo-mechanical effects and their influence on the transport properties of fractured rock. Keynote lecture. Proc. $11^{\text {th }}$ International Conference on Computer Methods and Analysis in Geomechanics. Turin, June. Vol. 3 pp. 517-530. [Keynote Lecture].

3. Elsworth, D. and others (2004) Mechanical and chemical controls on the evolution of fracture transport and chemical properties. Keynote presentation. European Rock Physics Conference. Berlin. September. [Keynote Lecture].

4. Elsworth, D. (2003) Hydromechanical and hydrochemical influences on the transport properties of fractured reservoirs. Invited plenary. ARMA-DoE Workshop on Rock Mechanics and Enhanced Geothermal Systems. Cambridge, MA, USA, June 20. [Keynote Lecture].

5. Elsworth, D., Grader, A.S., Halleck, P., Liu, J., Polak, A.B., and Yasuhara, H. (2003) Some THMC controls on the evolution of fracture permeability. Keynote Presentation. GeoProc 2003. Proc. Int. Conf. on Coupled T-H-M-C Processes in Geosystems. Stockholm, Sweden, October, p. 58. [Keynote Lecture].

\subsection{Abstracts and Presentations}

1. Elsworth, D. (2007) Evolution of the Mechanical and Transport Properties of Fractures: Interactive Feedbacks of Stress and Chemistry. Invited. SIAM Conf. on Mathematical and Computational Issues in the Geosciences. Santa Fe, MN, March. [Invited].

2. Elsworth, D., Yasuhara, H., Liu, J., Polak, A., Grader, A., Halleck, P. 2005. Constrained observation of stress- and chemistry-mediated chages in the transport properties of fractured rock via physical and chemical signals supplemented by X-ray CT. EOS AGU Trans. (Dec AGU Mtg). [Invited].

3. Elsworth, D. (2005) Stress- and chemistry-mediated changes in the mechanical and transport properties of porous and fractured rocks: observations and some unanswered questions. Annual Meeting of the Geothermal Research Society of Japan, Obama, Nagaskai, Japan, November. [Invited].

4. Elsworth, D. (2005) Stress- and chemistry-mediated changes in the mechanical and transport properties of porous and fractured rocks: observations and some unanswered questions. Third International Workshop on Water Dynamics, Sendai, Japan, November. [Invited].

5. Elsworth, D. (2005) Stress- and chemistry-mediated changes in the mechanical and transport properties of porous and fractured rocks: observations and some unanswered questions. ExxonMobil Research and Engineering, Annandale, New Jersey, July $26^{\text {th }}$. [Invited].

6. Polak, A., H. Yasuhara, D. Elsworth, Y. Mitani, A. S.Grader, and P. M. Halleck (2004) Quantification of contact area and aperture distribution of a single fracture by combined X-ray CT and laser profilometry. Symposium of Dynamics of fluids in Fractured Rocks. Berkeley, CA, February.

7. Yasuhara et al., (2003), Polak et al., (2003), and Liu et al., (2003). Presentations at GeoProc 2003, detailed above. 
8. Elsworth, D. (2003) Coupled THMCB processes in fractured rocks: flow and transport properties. School of Oil and Gas, University of Western Australia, March 18, 2003, and CSIRO Exploration and Mining, Brisbane, March 25.

9. Elsworth, D. (2003) Evolution of permeability in natural fractures: X-ray CT characterization. School of Engineering, Griffith University, Brisbane, March 26.

10. Polak, A. (2003) Quantitative imaging of flow and transport in fractured rocks. Invited Presentations. Israel Geological Survey, Jerusalem; Ben-Gurion University of the Negev; Technion - Israel Institute of Technology, Israel.

11. Polak, A. M. Landon, A. S. Grader, and D. Elsworth (2003) Detection of bacteria in porous media using X-ray computed tomography. Geophysical Research Abstracts, Joint EGS/AGU Meeting, Nice, April.

12. Polak, A., D. Elsworth, J. Liu, and A.S. Grader (2002) Spontaneous switching of permeability changes in a limestone fracture under net dissolution. Eos. Trans. AGU, 83(47), Fall Meeting Suppl., Abstract H62G-10.

13. Elsworth, D., A. Polak, A.S. Grader, H. Yasuhara, P.M. Halleck, and S.L. Brantley (2002) Quantitative Constrained Imaging of dissolution and precipitation in natural fractures. Eos Trans. AGU, 83(47), Fall Meeting, Suppl., Abstract H71B-0801.

14. Elsworth, D. (2002) Some needs and potential benefits related to a national underground science laboratory. NUSL-Geo-hydrology Engineering Team. NSF-ARMA/NeSS Workshop on Potential Benefits of a National Underground Science Laboratory, Washington, D.C., 18 September, and NSF-NeSS Workshop on Neutrinos and Subterranean Science, Washington, D.C., 19-21 September.

15. Elsworth, D., Polak, A., Yasuahra, H., Grader, A.S., Brantley, S.L., and Halleck, P. (2001) X-Ray CT imaging of changes in permeability due to dissolution and precipitation in fractured Berea sandstone. Multiscale Reservoir Symposium, Lawrence Berkeley National Laboratory, December $7-8,2001$.

\subsection{Awards and Honors}

1. Hideaki Yasuhara. 2006 Recipient of the ARMA N.G.W. Cook Ph.D. Award in Rock Mechanics.

2. Hideaki Yasuhara. 2007 Recipient of the Rocha Medal from ISRM. 